\title{
Dynamic annuloplasty for mitral regurgitation
}

\author{
Frank Langer, MD, ${ }^{\mathrm{a}}$ Michael A. Borger, MD, ${ }^{\mathrm{b}}$ Markus Czesla, MD, ${ }^{\mathrm{c}}$ Francis L. Shannon, MD, ${ }^{\mathrm{d}}$ \\ Mark Sakwa, MD, ${ }^{\mathrm{d}}$ Nicolas Doll, MD,${ }^{\mathrm{c}}$ Jochen T. Cremer, MD, ${ }^{\mathrm{e}}$ F. W. Mohr, MD, ${ }^{\mathrm{b}}$ and H.-J. Schäfers, MD ${ }^{\mathrm{a}}$
}

Objective: The MiCardia DYANA annuloplasty system (MiCardia Corp, Irvine, Calif) is a nitinol-based dynamic complete ring that allows modification of the septal-lateral diameter under transesophageal echocardiography guidance in the loaded beating heart after mitral valve repair. Shape alteration is induced by radiofrequency via detachable activation wires. This multicenter study reports the first human experience with this device.

\begin{abstract}
Methods: Patients $(n=35,67 \pm 8$ years $)$ with degenerative $(n=29)$, functional/ischemic $(n=5)$, or rheumatic $(\mathrm{n}=1)$ mitral regurgitation underwent mitral valve repair using the new device. We analyzed the occurrence of death, endocarditis, ring dehiscence, systolic anterior motion, thromboembolism, pulmonary edema, heart block, ventricular arrhythmia, hemolysis, or myocardial infarction at 30 days (primary end point) and 6 months (secondary end point) postprocedure.
\end{abstract}

Results: All patients exhibited mitral regurgitation of 2 or less early postoperatively and at 6 months follow-up. In 29 patients, the initial mitral valve repair result was satisfactory and no ring activation was required. In 6 patients, the nitinol-based ring was deformed intraoperatively postrepair with further improvement of mitral regurgitation in all cases (preactivation: $0.9 \pm 0.2$, postactivation: $0.2 \pm 0.3 ; P=.001)$. One death $(2.9 \%$, multisystem organ failure, non-device related), 2 ventricular arrhythmias (5.7\%), and 1 heart block $(2.9 \%)$ occurred, all in the first 30 days after surgery. No additional major adverse clinical events occurred later than 1 month postprocedure (total observed major adverse clinical event rate $11.5 \%$ ).

Conclusions: The implantation of the new dynamic annuloplasty ring allows for safe mitral valve repair. The option of postrepair modification of the septal-lateral diameter by radiofrequency may further optimize repair results. (J Thorac Cardiovasc Surg 2013;145:425-9)

Mitral valve (MV) repair has become recognized as the procedure of choice for mitral regurgitation (MR) of any cause, ${ }^{1-3}$ including those with cardiomyopathy and functional MR. ${ }^{4}$ Standard MV repair usually includes the implantation of an annuloplasty ring, ${ }^{2-5}$ because remodeling of the mitral annulus by ring annuloplasty improves the durability of the repair. ${ }^{6}$ One of the major determinants of recurrent MR post-MV repair is the presence of residual MR in the operating room. ${ }^{6}$ Thus, the surgeon should aim for a near perfect repair with trivial or no $\mathrm{MR}$ at the end of the procedure. Residual MR $2+$ or greater should not be tolerated and may require further repair attempts or MV replacement during repeat aortic

\footnotetext{
From the Department of Thoracic and Cardiovascular Surgery, ${ }^{a}$ University Hospital Homburg, Germany; Department of Cardiovascular Surgery, ${ }^{\mathrm{b}}$ Heart Center Leipzig, Germany; Department of Cardiovascular Surgery, ${ }^{\mathrm{c}}$ Sana Hospital Stuttgart, Germany; Department of Cardiovascular Surgery, ${ }^{d}$ Beaumont Hospital, Royal Oak, Mich; and Department of Cardiovascular Surgery, ${ }^{\text {e }}$ University Hospital Kiel, Germany.

The study was sponsored by MiCardia Corporation (Irvine, Calif).

Disclosures: Authors have nothing to disclose with regard to commercial support.

Received for publication July 5, 2011; revisions received Oct 23, 2011; accepted for publication Dec 14, 2011; available ahead of print Feb 27, 2012.

Address for reprints: Frank Langer, MD, Department of Thoracic and Cardiovascular Surgery, Kirrberger Str, Bldg 57, Suite E 68, University Hospital Homburg, Germany (E-mail: frank.langer@uks.eu).

$0022-5223 / \$ 36.00$

Copyright (c) 2013 by The American Association for Thoracic Surgery doi:10.1016/j.jtcvs.2011.12.062
}

crossclamping. The risk of recurrent MR may need to be weighed against the risk of prolonged ischemic time and postoperative myocardial dysfunction, particularly in patients with preoperative impaired left ventricular function.

Residual or recurrent MR occurs in $30 \%$ of patients after undersized ring annuloplasty for functional MR..$^{7-9}$ Experimental studies have emphasized that reduction of the septal-lateral diameter reduces functional MR..$^{10,11}$ Thus, further reduction of the septal-lateral diameter may be desirable if residual MR is observed on postrepair transesophageal echocardiography (TEE).

Systolic anterior motion (SAM) of the anterior mitral leaflet may complicate repair of degenerative MR. If standard treatment with volume loading, avoidance of inotropes, and beta-blockade fails, implantation of a larger ring may be required. Thus, increase of the septal-lateral diameter may be desirable to eliminate this life-threatening complication in some patients.

With the use of an adjustable annuloplasty ring, an imperfect MV repair may be optimized by altering the septal-lateral diameter in the loaded beating heart under echocardiographic guidance. The objective of this study was to assess the safety and efficacy of a new deformable nickel-titanium (Nitinol)-based annuloplasty ring (DYANA Dynamic Annuloplasty Ring System; MiCardia Corp, Irvine, Calif) in a prospective, multicenter trial. 


$$
\begin{aligned}
& \text { Abbreviations and Acronyms } \\
& \begin{aligned}
\text { CPB = } & \text { cardiopulmonary bypass } \\
\text { DYANA = } & \text { Dynamic Annuloplasty System with } \\
& \text { Activation for the Treatment of Mitral } \\
& \text { Regurgitation } \\
\text { MACE = } & \text { major adverse clinical event } \\
\text { MR = } & \text { mitral regurgitation } \\
\text { MV = } & \text { mitral valve } \\
\text { NYHA = } & \text { New York Heart Association } \\
\text { SAM = } & \text { systolic anterior motion } \\
\text { TEE }= & \text { transesophageal echocardiography }
\end{aligned}
\end{aligned}
$$

\section{MATERIALS AND METHODS}

The Dynamic Annuloplasty System with Activation for the Treatment of Mitral Regurgitation (DYANA) study was designed as a multicenter, nonrandomized, single-arm clinical trial and conducted in accordance with the Declaration of Helsinki, with Good Clinical Practice guidelines, local regulations, and ISO 14155 specifications. Clinical data were obtained on 35 patients treated with the MiCardia Dynamic Annuloplasty Ring System in 5 surgical centers (Homburg $n=7$, Leipzig $n=11$, Stuttgart $\mathrm{n}=8$, Kiel $\mathrm{n}=4$, Royal Oak $\mathrm{n}=5$ ). The study was approved by local ethics committees in each surgical center. Informed consent was obtained from each patient before undergoing any procedure or preoperative evaluation specific to this protocol.

Evaluation included transthoracic or transesophageal echocardiographic assessment of MR and heart rhythm before implantation, at the time of implantation, at hospital discharge, at 30 days, and at 6 months postprocedure. MR was quantified using the ratio of regurgitant jet area/ left atrial area, vena contracta, or proximal isovelocity surface area by a core echo laboratory. In addition, a complete blood count, brain natriuretic peptide, lactate dehydrogenase, hematocrit, and creatinine were measured preoperatively and 6 months postimplantation. The anticoagulation regimen was according to local practice at each investigational site.

\section{Device}

The MiCardia DYANA annuloplasty device (MiCardia enCor Mitral Valve Repair System) is a rigid complete ring available in sizes 28 to 36 $\mathrm{mm}$ (Figures 1 and 2). Without radiofrequency activation, it functions as a standard complete annuloplasty ring. The nitinol support is encapsulated in silicone and covered with a polyester cloth to allow for suture attachment and to promote tissue ingrowth and healing. The device is otherwise constructed with commercially available annuloplasty ring materials and has been tested for biocompatibility. By using radiofrequency energy, the nitinol support can be heated to effect a change in shape allowing shortening (D- device) or lengthening (D+ device) of the septal-lateral distance by 0.5 to $3.0 \mathrm{~mm}$ and the intercommissural distance by 1.0 to $3.5 \mathrm{~mm}$ (Figure 3 ). The shape alteration during ring activation is a non-reversible, unidirectional process. Intraoperative activation wires were used for delivery of energy to the annuloplasty ring for activation purposes. The distal ends of the wires were attached to the annuloplasty ring, and the proximal ends were attached to a radiofrequency generator. After surgical implantation of the annuloplasty ring, the proximal ends of the activation wires were passed through the atriotomy, the left atrium was closed, and the patient was weaned from cardiopulmonary bypass (CPB). If TEE examination revealed residual MR, the surgeon could apply the radiofrequency current to activate the ring. The activation wires were disengaged and removed through the atriotomy suture line at the end of the procedure in all patients before closure of the sternum.

\section{Study End Points}

Primary and secondary safety end points were defined as the occurrence of death, endocarditis, ring dehiscence, SAM, thromboembolism, pulmonary edema, heart block, arrhythmia, hemolysis, or myocardial infarction at 30 days and 6 months postprocedure.

The primary efficacy end point was defined as the ability to reduce MR to less than $2+$ immediately after surgical implantation of the annuloplasty device. The secondary efficacy end point was defined as the ability to further reduce residual MR after intraoperative activation of the device.

\section{RESULTS \\ Patient Data}

Thirty-five patients received the study device between December 2008 and September 2009. Mean age was $67 \pm$ 8 years, the majority of patients were male $(22 / 35$ or $62.9 \%)$, mean height was $171 \pm 9 \mathrm{~cm}$, and average weight was $77 \pm 15 \mathrm{~kg}$. Eleven patients (31.4\%) were in New York Heart Association (NYHA) class II functional class, 23 patients $(65.7 \%)$ were in NYHA class III, and 1 patient $(2.9 \%)$ was in NYHA class IV. Cause of MR was degenerative in 29 patients, functional in 5 patients, and rheumatic in 1 patient. Pulmonary hypertension was present in 9 of 35 patients, and atrial fibrillation was present in 15 of 35 patients. Relevant comorbidities were hypertension (22/35), coronary artery disease (9/35), previous myocardial infarction (3/35), cardiomyopathy (4/35), hyperlipidemia (12/ $35)$, chronic obstructive pulmonary disease (4/35), and diabetes $(3 / 35)$.

\section{Operative Data}

Surgery was performed with standard techniques using median sternotomy and standard CPB cannulation in 18 of 35 patients and minimally invasive techniques via a right mini-thoracotomy in 17 of 35 patients. Mean CPB time was $132 \pm 44$ minutes, and myocardial ischemic time was $82 \pm$ 32 minutes. Median ring size was $32 \mathrm{~mm}$ (range, 28-36 $\mathrm{mm}$ ). Thirty implanted annuloplasty ring systems were of type D-, and 5 implanted devices were of type D+. Concomitant procedures consisted of tricuspid valve repair $(n=9)$, atrial ablation $(\mathrm{n}=15)$, coronary artery bypass grafting $(n=7)$, aortic valve replacement $(n=2)$, aortic valve repair, and ascending aortic replacement $(n=1)$. The operation was a redo procedure in 1 patient who previously underwent coronary artery bypass grafting.

\section{Safety End Points}

One patient died 2 days after surgery. The primary cause of death was multisystem organ failure and was considered noncardiac and non-device related. In total, 1 death $(2.9 \%)$, 2 ventricular arrhythmias (5.7\%), and 1 heart block (2.9\%) occurred, all within the first 30 days following device implantation. No additional major adverse clinical events (MACE) occurred later than 1 month postprocedure. Therefore, the total observed MACE rate was $11.5 \%$ (4 events in 35 patients). 


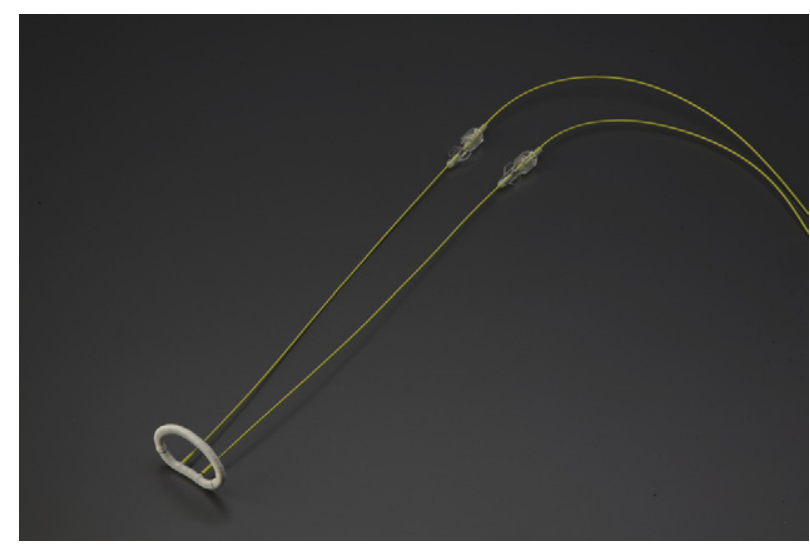

FIGURE 1. Schematic of the dynamic annuloplasty device.

\section{Efficacy End Points}

Residual MR was detected intraoperatively during the postrepair TEE in 6 patients. Decrease of the septallateral diameter $(\mathrm{D}-$ in all 6 cases) in the beating heart post-CPB (Table 1) improved MR in all 6 patients (preactivation: $0.9 \pm 0.2$, postactivation: $0.2 \pm 0.3 ; P=.001$ by paired $t$ test). None of the patients receiving $\mathrm{D}+$ devices required activation for treatment of SAM.

At postprocedural investigation, all patients exhibited MR less than 2+. Six months after surgery, 16 patients (47.1\%) had no MR, 7 patients $(20.6 \%)$ had trace MR, 7 patients $(20.6 \%)$ had MR grade $1+$, and 3 patients had MR grade $2+(8.8 \%)$. All 3 patients with MR grade $2+$ had MR grade $3+$ before surgery. Detailed MR data at all study time points are provided in Table 2 .

\section{DISCUSSION}

The primary objective of this study was to evaluate the safety and efficacy of a new dynamic, radiofrequencyactivated annuloplasty device in a patient population undergoing MV repair with or without concomitant procedures. One of the cornerstones of MV repair is the implantation of an annuloplasty ring device. Ring implantation improves

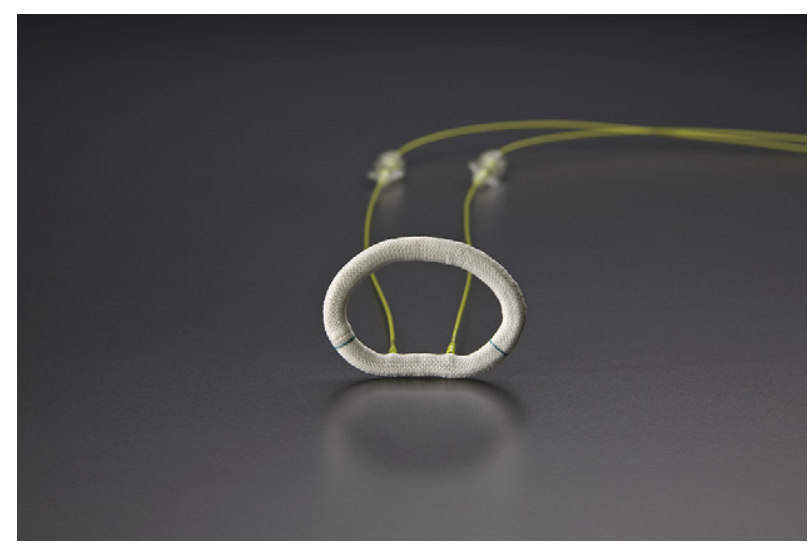

FIGURE 2. Schematic of the dynamic annuloplasty device.
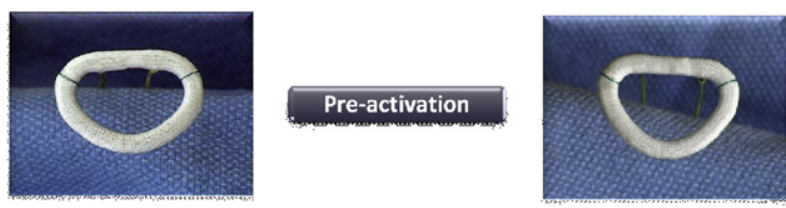

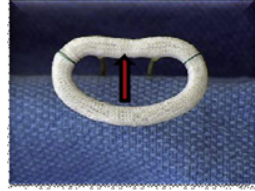

D- (Ischemic)

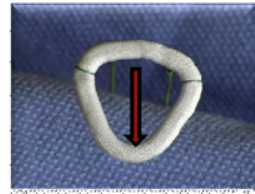

D + (Degenerative)
FIGURE 3. Schematic of the 2 subtypes of the dynamic annuloplasty device: The $\mathrm{D}$ - shaped device has been designed for patients with functional MR and allows reduction of the septal-lateral dimension in the loaded beating heart postrepair if residual MR is encountered. The D+shaped device is intended for patients with degenerative MR and allows increase of the septal-lateral dimension if SAM is encountered postrepair.

leaflet coaptation by reducing annular area, and subsequently results in less residual MR in the perioperative phase. ${ }^{1}$ The use of an annuloplasty ring also minimizes future recurrent MR by decreasing forces on the leaflets and subvalvular apparatus during systole, as well as by preventing future annular dilatation. Several ring devices have been developed, and their results have been extensively reported. $^{12-17}$ Ring design may be partial or complete; flexible, semi-flexible, or rigid; or disease-specific (eg, IMR-ETLogix, Myxo-ETlogix, Edwards Lifesciences, Irvine, Calif). ${ }^{18,19}$ However, none of these annuloplasty rings allow major intrinsic shape changes during or postimplantation.

MV repair for functional MR due to ischemic or dilative cardiomyopathy continues to be a challenge for cardiac surgeons. Residual or recurrent MR is observed in up to $30 \%$ of patients. ${ }^{7-9,20}$ Standard treatment for functional MR includes undersized ring annuloplasty. Annular dilatation is seen in all patients with functional MR, and experimental studies have demonstrated that septal-lateral cinching eliminates functional MR. ${ }^{10,11}$ Some patients

TABLE 1. Intraoperative data from 6 patients who underwent activation of a D-shaped dynamic annuloplasty device

\begin{tabular}{lcccccc}
\hline $\begin{array}{c}\text { Patient } \\
\text { no. }\end{array}$ & Disease & $\begin{array}{c}\text { BSA } \\
\left(\mathbf{m}^{\mathbf{2}}\right)\end{array}$ & $\begin{array}{c}\text { ring } \\
(\mathbf{m m})\end{array}$ & $\begin{array}{c}\text { MR } \\
\text { before }\end{array}$ & $\begin{array}{c}\text { MR } \\
\text { after }\end{array}$ & $\begin{array}{c}\text { MR } \\
\text { activity }\end{array}$ \\
\hline 1 & FMR & 2.18 & 34 & 3 & 1 & 0 \\
2 & DMR & 1.51 & 34 & 4 & 1 & 0.5 \\
3 & FMR & 2.13 & 34 & 2 & 0.5 & 0 \\
4 & FMR & 1.72 & 32 & 4 & 1 & $0 *$ \\
5 & DMR & 2.02 & 30 & 3 & 1 & 0 \\
6 & DMR & 1.95 & 30 & 3 & 1 & 0 \\
\hline
\end{tabular}

$F M R$, Functional mitral regurgitation; $D M R$, degenerative mitral regurgitation; $M R$, mitral regurgitation; $B S A$, body surface area. *Papillary muscle repositioning with a STRING technique ${ }^{23}$ already reduced MR from 1 to 0.5 . $^{\circ}$ 
TABLE 2. Summary of mitral regurgitation grade by time interval

\begin{tabular}{lcrr}
\hline Time point & MR grade & N & $\%$ \\
\hline 1. Preprocedural & 2 & 3 & 9 \\
& 3 & 23 & 66 \\
2. Postprocedural & 4 & 9 & 26 \\
& 0 & 26 & 74 \\
3. Discharge & $0-1$ & 8 & 23 \\
& 1 & 1 & 3 \\
& 0 & 26 & 77 \\
4. Follow-up 30 d & $0-1$ & 4 & 12 \\
& 1 & 2 & 6 \\
& Missing & 2 & 6 \\
& 0 & 13 & 38 \\
5. Follow-up 6 mo & $0-1$ & 8 & 24 \\
& 1 & 3 & 9 \\
& 2 & 2 & 6 \\
& Missing & 8 & 24 \\
& 0 & 16 & 47 \\
& $0-1$ & 7 & 21 \\
& 1 & 7 & 21 \\
& 2 & 3 & 9 \\
& Missing & 1 & 3 \\
\hline m. & & &
\end{tabular}

$M R$, Mitral regurgitation.

also exhibit severe leaflet tethering due to papillary muscle displacement. Adjunctive repair techniques, such as cutting of second order chordae, ${ }^{21}$ leaflet extension, ${ }^{22}$ or papillary muscle repositioning, ${ }^{23}$ have been proposed to relieve leaflet tethering. Most surgeons, however, continue to rely on implantation of an undersized complete ring device. This concept of aggressive undersizing for functional MR is based on the Bolling concept ${ }^{4}$ and includes downsizing by at least 2 sizes in relation to the intertrigonal distance. Recent studies have demonstrated that aggressive downsizing may lead to functional mitral stenosis with decreased functional capacity and elevated pulmonary artery pressures. ${ }^{24,25}$ Accordingly, aggressive undersizing has been regarded by some as patient prosthesis-mismatch for MV repair. Concerns regarding induced mitral stenosis, combined with the relatively high incidence of observed MR recurrence, have led some cardiac surgeons to search for other alternatives to the undersized annuloplasty operation. The use of a dynamic annuloplasty ring could be an appealing alternative for patients with functional MR. The surgeon could initially choose a mild to moderately undersized ring with a greater annular area. If residual MR is encountered during intraoperative TEE, the septal-lateral distance can be tailored postrepair under TEE guidance in the loaded beating heart.

MV repair for degenerative disease also involves the insertion of a ring annuloplasty device in the majority of patients. The ring device is usually sized according to the size of the anterior leaflet. A typical complication of MV repair surgery for degenerative disease is SAM of the anterior mitral leaflet, leading to left ventricular outflow tract obstruction. This potentially life-threatening complication occurs in approximately $10 \%$ to $15 \%$ of patients after MV repair ${ }^{26,27}$ and may be precipitated by the use of complete undersized rings, excessive leaflet tissue (Barlow's disease) with inadequate height of the posterior mitral leaflet, hypovolemia, and excessive inotropic support. Alternative ring design in the Edwards MyxoETlogix ring with increased septal-lateral diameter intends to avoid SAM in patients with myxomatous valves. ${ }^{19}$ The option of increasing septal-lateral distance postrepair in case of SAM by using a dynamic ring (D+) may thus be an appealing alternative.

The DYANA annuloplasty device is a complete rigid ring available in sizes 28 to $36 \mathrm{~mm}$. The new device uses a nickel-titanium (Nitinol) metallic support for rigidity and shaping. If postrepair TEE reveals residual MR, the repair can be improved through a modification of septallateral diameter using radiofrequency activation. Indeed, we observed a significant reduction in MR grade in the 6 patients who required ring activation postrepair (from $0.9 \pm$ 0.2 to $0.2 \pm 0.3, P=.001$ ). Follow-up echocardiography also revealed good results with all patients having $1+$ or less MR during predischarge examination, and all but 3 patients having $1+$ or less MR during 6 months follow-up. No patient had more than $2+$ MR at any time during the study period.

The DYANA mitral annuloplasty device allows for adjustments to the ring size and shape under physiologic conditions, that is, when the heart is fully loaded and separated from CPB. In addition, changes in ring size can be achieved in a matter of seconds and do not require any additional $\mathrm{CPB}$ or myocardial ischemic time, in contrast with conventional surgical techniques. Removal of the activation wires through the closed left atrial incision was performed before chest closure and was uneventful in all patients in the current study, regardless if surgical access was performed via a standard median sternotomy or minimally invasively. Future device advancements will focus on the development of a subcutaneous activation wire system, which could be activated any time during patient follow-up. The second generation of the current device will allow postrepair activation up to 6 months postoperatively and is currently being investigated in a multicenter study. Such a device may be particularly helpful in patients with functional MR, because recurrent $\mathrm{MR}$ is known to occur months to years postsurgery in a significant proportion of such patients. ${ }^{7-9}$

Previous in vitro and in vivo studies have demonstrated that activation with maximal power will result in an increase of the device surface temperature of $1{ }^{\circ} \mathrm{C}$ to $2^{\circ} \mathrm{C}$, even at low-flow conditions. Chronic animal studies revealed that the radiofrequency activation does not cause damage, such as thermal injury or necrosis, to surrounding tissue or blood cells. In addition, significant hemolysis was not encountered in the present investigation. Our 
observed MACE event rate $(11.5 \%)$ falls within the expected range for this patient population undergoing MV repair. ${ }^{28,29}$

We can therefore conclude that the implantation of a novel dynamic, radiofrequency-activated annuloplasty device allows for safe MV repair, with or without device activation. Annuloplasty device activation is associated with an improvement in MR grade in patients with intraoperative residual MR. Further investigations will be required to determine whether such intraoperative activations lead to improved medium- and long-term durability of MV surgery, particularly for patients with functional MR.

\section{Study Limitations}

The main limitation of the current study was the lack of a control group. However, the trial was designed as firstin-human, multicenter, prospective study to assess device safety. Despite the fact that device safety was the primary outcome, we were able to demonstrate device efficacy in a small number of patients with residual MR. Unfortunately, there was a significant number of absent patients at the 30-day follow-up visit; however, the late follow-up was $97 \%$ complete.

All modifications of septal-lateral diameter by activation of the nitinol-based ring in this study were made in patients receiving $\mathrm{D}$ - rings if residual MR was encountered during postrepair TEE. Because none of the patients presented with SAM, none of the D+ rings had been activated. Thus, we can only speculate on salutary effects of increasing the septal-lateral diameter for treatment of SAM.

The authors thank Drs Ottavio Alfieri and Maurice Buchbinder for contributions in the design and development of the novel dynamic annuloplasty device.

\section{References}

1. Carpentier A. Cardiac valve surgery-the "French correction". J Thorac Cardiovasc Surg. 1983;86:323-37.

2. Gillinov AM, Cosgrove DM. Mitral valve repair for degenerative disease. $J$ Heart Valve Dis. 2002;11(Suppl 1):S15-20.

3. Cohn LH. Surgery for mitral regurgitation. JAMA. 1988;260:2883-7.

4. Bolling SF. Mitral reconstruction in cardiomyopathy. J Heart Valve Dis. 2002; 11(Suppl 1):S26-31.

5. Lawrie GM. Mitral valve repair vs replacement. Current recommendations and long-term results. Cardiol Clin. 1998;16:437-48.

6. Suri RM, Schaff HV, Dearani JA, Sundt TM III, Daly RC, Mullany CJ, et al. Survival advantage and improved durability of mitral repair for leaflet prolapse subsets in the current era. Ann Thorac Surg. 2006;82:819-26.

7. Tahta SA, Oury JH, Maxwell JM, Hiro SP, Duran CM. Outcome after mitral valve repair for functional ischemic mitral regurgitation. $J$ Heart Valve Dis. 2002;11:11-8.

8. Matsunaga A, Tahta SA, Duran CM. Failure of reduction annuloplasty for functional ischemic mitral regurgitation. J Heart Valve Dis. 2004;13:390-7.
9. McGee EC, Gillinov AM, Blackstone EH, Rajeswaran J, Cohen G, Najam F, et al. Recurrent mitral regurgitation after annuloplasty for functional ischemic mitral regurgitation. J Thorac Cardiovasc Surg. 2004;128:916-24.

10. Timek TA, Lai DT, Tibayan F, Liang D, Daughters GT, Dagum P, et al. Septallateral annular cinching abolishes acute ischemic mitral regurgitation. J Thorac Cardiovasc Surg. 2002;123:881-8.

11. Tibayan FA, Rodriguez F, Langer F, Zasio MK, Bailey L, Liang D, et al. Does septal-lateral annular cinching work for chronic ischemic mitral regurgitation? J Thorac Cardiovasc Surg. 2004;127:654-63.

12. Carpentier AF, Lessana A, Relland JY, Belli E, Mihaileanu S, Berrebi AJ, et al The "physio-ring": an advanced concept in mitral valve annuloplasty. Ann Thorac Surg. 1995;60:1177-85.

13. Cosgrove DM III, Arcidi JM, Rodriguez L, Stewart WJ, Powell K, Thomas JD Initial experience with the Cosgrove-Edwards Annuloplasty System. Ann Thorac Surg. 1995;60:499-503.

14. Kshettry VR, Kanda LT. Prospective study of mitral valve repair with the CarboMedics AnnuloFlex annuloplasty system: effectiveness and safety after one year. J Heart Valve Dis. 2005;14:105-13.

15. Seguin JR, Demaria R, Rogier R, Chaptal PA. Advance in mitral valve repair using a device flexible in three dimensions. The St Jude Medical-Seguin annuloplasty ring. ASAIO J. 1996;42:M368-71.

16. Chang BC, Youn YN, Ha JW, Lim SH, Hong YS, Chung N. Long-term clinical results of mitral valvuloplasty using flexible and rigid rings: a prospective and randomized study. J Thorac Cardiovasc Surg. 2007;133:995-1003.

17. Okada Y, Shomura T, Yamaura Y, Yoshikawa J. Comparison of the Carpentier and Duran prosthetic rings used in mitral reconstruction. Ann Thorac Surg. 1995;59:658-62.

18. Daimon M, Fukuda S, Adams DH, McCarthy PM, Gillinov AM, Carpentier A, et al. Mitral valve repair with Carpentier-McCarthy-Adams IMR ETlogix annuloplasty ring for ischemic mitral regurgitation: early echocardiographic results from a multi-center study. Circulation. 2006;114(1 Suppl):I588-93.

19. McCarthy PM, McGee EC, Rigolin VH, Zhao Q, Subacius H, Huskin AL, et al Initial clinical experience with Myxo-ETlogix mitral valve repair ring. J Thorac Cardiovasc Surg. 2008;136:73-81.

20. Lee AP, Acker M, Kubo SH, Bolling SF, Park SW, Bruce CJ, et al. Mechanisms of recurrent functional mitral regurgitation after mitral valve repair in nonischemic dilated cardiomyopathy: importance of distal anterior leaflet tethering. Circulation. 2009;119:2606-14.

21. Borger MA, Murphy PM, Alam A, Fazel S, Maganti M, Armstrong S, et al. Initial results of the chordal-cutting operation for ischemic mitral regurgitation. $J$ Thorac Cardiovasc Surg. 2007;133:1483-92.

22. de Varennes B, Chaturvedi R, Sidhu S, Cote AV, Shan WL, Goyer C, et al. Initial results of posterior leaflet extension for severe type IIIb ischemic mitral regurgitation. Circulation. 2009;119:2837-43.

23. Langer F, Kunihara T, Hell K, Schramm R, Schmidt KI, Aicher D, et al. RING+ STRING: successful repair technique for ischemic mitral regurgitation with severe leaflet tethering. Circulation. 2009;120(11 Suppl):S85-91.

24. Magne J, Senechal M, Mathieu P, Dumesnil JG, Dagenais F, Pibarot P. Restrictive annuloplasty for ischemic mitral regurgitation may induce functional mitral stenosis. J Am Coll Cardiol. 2008;51:1692-701.

25. Kubota K, Otsuji Y, Ueno T, Koriyama C, Levine RA, Sakata R, et al. Functional mitral stenosis after surgical annuloplasty for ischemic mitral regurgitation: importance of subvalvular tethering in the mechanism and dynamic deterioration during exertion. J Thorac Cardiovasc Surg. 2010;140:617-23.

26. Creszenzi G, Landoni G, Zangrillo A, Guarracino F, Rosica C, La Canna G, et al Management and decision making for systolic anterior motion after mitral repair J Thorac Cardiovasc Surg. 2009;137:320-5.

27. Brown ML, Abel MD, Click RL, Morford RG, Dearani JA, Sundt TM, et al. Systolic anterior motion after mitral repair: is surgical intervention necessary? $J$ Thorac Cardiovasc Surg. 2007;133:136-43.

28. Gillinov AM, Mihaljevic T, Blackstone EH, George K, Svensson LG, Nowicki ER, et al. Should patients with severe degenerative mitral regurgitation delay surgery until symptoms develop? Ann Thorac Surg. 2010;90:481-8.

29. Acker MA, Jessup M, Bolling SF, Oh J, Starling RC, Mann DL, et al. Mitral valve repair in heart failure: five-year follow-up from the mitral valve replacement stratum of the Acorn randomized trial. J Thorac Cardiovasc Surg. 2011;142:569-74. 